\title{
SAÚDE MENTAL DISCENTE NA EDUCAÇÃO PROFISSIONAL E
} TECNOLÓGICA: EXPERIÊNCIAS DE ESTUDANTES E DOCENTES DOS CURSOS TÉCNICOS INTEGRADOS

Josiane de Paula Jorge Tsunematsu ${ }^{1}$

Rodrigo Palucci Pantoni ${ }^{2}$

Fabiana Maris Versuti ${ }^{3}$

DOI: https://doi.org/10.36524/profept.v5i2.753

\section{Resumo}

Este artigo é fruto de uma pesquisa qualitativa, cujo objetivo foi desvelar as experiências dos discentes dos Cursos Técnicos Integrados ao Ensino Médio, de um Câmpus do Instituto Federal de São Paulo, no que concerne à saúde mental discente. Esta proposta originou, como produto educacional, uma formação continuada de docentes sobre a temática. Os instrumentos utilizados para a coleta de dados foram grupos focais e questionários online. Para os discentes pesquisados, a relação social, entre estes e a instituição, entre discentes e docentes, gera sofrimento. Já para os docentes é uma questão individual: do discente e de suas condições pessoais que antecedem à escola. O sofrimento psíquico discente está atrelado às contradições dadas pelas desigualdades sociais que atravessam a escola.

Palavras-chave: educação profissional e tecnológica; saúde mental; ensino médio integrado; psicologia escolar.

\section{STUDENT'S MENTAL HEALTH IN PROFESSIONAL AND TECHNOLOGICAL EDUCATION: EXPERIENCES OF STUDENTS AND TEACHERS FROM INTEGRATED TECHNICAL COURSES}

\begin{abstract}
This article is the work of a qualitative research, which objetive is to unveil the experiences of the students from the Integrated techinical course to the high school of one of the Federal Institute of São Paulo Campus, in matters of the student's mental health. This proposal originated an educational product: a continuous teacher's formation about the student's mental health in the context of the Professional and Tecnological Education. The instruments used to gatter the data were focal groups and online questionaries. For the researched students, the social relationship between students and institution, between students and teachers, generates
\end{abstract}

\footnotetext{
${ }^{1}$ Instituto Federal de São Paulo - IFSP. E-mail: josianepjorge@ hotmail.com

${ }^{2}$ Instituto Federal de São Paulo - IFSP. E-mail: rpantoni@ifsp.edu.br

${ }^{3}$ Universidade de São Paulo - USP - Ribeirão Preto. E-mail: fabiana_versuti@ usp.br
} 
sorrow. For the teachers it is an individual matter: of the student and their personal condition that precede school. The students' psychic suffering is attached to the conditions given due social inequalities throughout school.

Keywords: technological professional education; mental health; integrated technician high school course; school psychology.

\section{INTRODUÇÃO}

Nos Institutos Federais (IFs), os(as) psicólogos(as) escolares se deparam com diversas queixas: problemas de aprendizagem, comportamento, entre outras. Existe uma demanda recorrente de discentes com queixas emocionais e psicológicas que chegam até a Coordenadoria Sociopedagógica (CSP) ou equivalente nos IFs (JORGE, 2018; FARIA, 2017; SODRÉ 2017). A atuação da psicologia nestes casos não se configura como atuação clínica psicoterapêutica, mas como escuta, acolhimento e orientação, além de ser uma atuação voltada para o coletivo e não individualizada, tendo em vista a perspectiva da psicologia escolar/educacional (MARINHO-ARAÚJO; ALMEIDA, 2010).

Com isso, são recebidos discentes encaminhados por docentes, ou mesmo seus familiares, cujas queixas dizem respeito à ansiedade, questões emocionais e familiares, bem como dificuldade de adaptação ao curso e ao ritmo de atividades, principalmente do Ensino Médio Integrado (EMI) (JORGE, 2017, 2018). Os discentes ingressantes do EMI percebem o ambiente escolar dos IFs como gerador de angústia, ansiedade e estresse. Enfrentam, nesse processo de adaptação, experiências de intenso sofrimento psíquico (BRITO, 2017; FARIA 2017; SODRÉ, 2017). Assim, além do acolhimento ao discente, o(a) psicólogo(a) escolar é também requerido a orientar os docentes e familiares sobre estas demandas (JORGE, 2018).

Diante deste cenário, emergiu a motivação para estudar sobre a promoção da saúde mental dos discentes do EMI. O pesquisador, que quer trabalhar com aspectos da subjetividade dos sujeitos inseridos no contexto da Educação Profissional e Tecnológica (EPT), deve estar consciente de uma educação voltada para a promoção da plena manifestação humana, ou seja, da omnilateralidade (SAVIANI, 2003, 2007). E neste sentido, a saúde mental é uma dimensão humana que deve ser considerada.

Destarte, neste artigo são apresentados alguns resultados de uma pesquisa desenvolvida no Programa de Pós-Graduação em Educação Profissional e Tecnológica (ProfEPT) e que teve como objetivo desvelar as experiências dos discentes do EMI de um Câmpus do Instituto 
Federal de São Paulo (IFSP), no que concerne à saúde mental, a fim de ampliar as ações para a promoção da saúde mental.

\section{METODOLOGIA}

A pesquisa foi desenvolvida com os cursos do EMI em Automação Industrial e em Química de um Câmpus do IFSP, cujas turmas estavam no final do primeiro ano do curso. Ambos os cursos têm duração de quatro anos, sendo que os três primeiros ocorrem no período vespertino e o quarto no período matutino. $\mathrm{O}$ ingresso aos cursos é feito anualmente, por meio de processo seletivo, sendo que $50 \%$ das vagas são destinadas a candidatos que cursaram o ensino fundamental em escola pública, conforme a lei 12.711 de 2012.

Os participantes da pesquisa foram 14 discentes do primeiro ano do EMI em Química e em Automação Industrial, escolhidos aleatoriamente, mediante convite da pesquisadora e do Diretor de Ensino do Câmpus, que se dispuserem, por livre vontade e autorização dos responsáveis, a participar; bem como 17 docentes que atuam com estes discentes e que também se dispuserem a participar. Os discentes participantes têm idade ente 14 e 16 anos, sendo 04 meninos e 10 meninas. Os 17 docentes participantes têm idade entre 30 e 56 anos, sendo 08 homens e 09 mulheres.

Os instrumentos de coleta de dados somente foram empregados após a aprovação do projeto de pesquisa pelo Comitê de Ética em Pesquisas (CEP-IFSP) e após as assinaturas dos termos de consentimento livre e esclarecido e dos termos de assentimento.

A coleta de dados com os discentes ocorreu a partir da realização de grupos focais e da aplicação de questionário online. O grupo focal, como um instrumento qualitativo, não utiliza

[...] amostras probabilísticas e nem visa estudar a frequência com que determinado comportamento ou opinião ocorre. Trata-se [...] de utilizar o grupo focal no entendimento de como se formam e se diferem as percepções, opiniões acerca de um fato (IERVOLINO; PELICIONI, 2001, p. 117).

Foram realizados dois grupos focais. O primeiro grupo teve a participação de oito discentes do EMI em Química, com duração de aproximadamente 80 minutos. Já o segundo grupo foi realizado com a participação de seis discentes, sendo quatro do EMI em Química e dois do EMI em Automação Industrial, com duração de aproximadamente 100 minutos. As atividades dos grupos foram gravadas em áudio e transcritas, posteriormente. 
Os participantes dos grupos focais receberam o questionário online via e-mail, após a atividade em grupo. Foram enviados questionários para todos que participaram dos grupos e foram obtidas 10 respostas. Dentre os discentes que responderam ao questionário online, $50 \%$ se declararam pardos, $30 \%$ brancos e $20 \%$ pretos. Desses discentes, $50 \%$ residem na cidade do Câmpus e 50\% em cidades vizinhas e se deslocam até a escola utilizando transporte fretado, como vans, em viagens de até meia hora. Dentre estes discentes, 50\% recebem auxílio transporte e alimentação, pelo programa de Assistência Estudantil, sendo que $60 \%$ residem com famílias em que apenas uma pessoa está atualmente empregada. Contando com esses discentes, $40 \%$ residem em quatro pessoas, $30 \%$ em três pessoas e $30 \%$ em cinco pessoas. Esses dados revelam parte da realidade social dos discentes participantes da pesquisa.

Para a coleta de dados com os docentes foi elaborado e aplicado um questionário online, cujo tema é a saúde mental dos discentes do EMI. Foram enviados questionários, via e-mail, para 29 docentes, obtendo um total de 17 respostas. Os 17 participantes possuem diferentes formações superiores: Engenharia Elétrica, Engenharia Mecânica, Ciência da Computação Química, Matemática, Artes, Educação Musical; Mestres em Linguística, em Ciências Sociais, em Educação, em Ciências Exatas e Doutores em Ciências. Desses, 15 possuem formação pedagógica ou licenciatura, tendo $6,7 \%$ desses realizado a formação no IF, $60 \%$ em outra instituição pública e 33,3\% em instituição privada. Entre os 17 participantes, dois são docentes e coordenadores de curso; 15 atuam em regime de dedicação exclusiva e dois trabalham 40 horas semanais. Dentre os participantes, $82,4 \%$ se declararam brancos, $11,8 \%$ pardos e $5,9 \%$ pretos. Dos docentes participantes, 07 trabalham no IF de um a três anos, 03 de três a cinco anos, 04 de cinco a 10 anos, 01 a mais de 10 anos e 02 a menos de um ano. Esses dados permitem constatar que os docentes e os discentes participantes desta pesquisa pertencem a grupos étnicos e classes sociais diferentes.

A análise e o tratamento dos dados se deram por meio do trabalho com eixos de análise e se organizou a partir das recomendações de Minayo (2012) sobre a análise em pesquisa qualitativa. Para Minayo (2012), o principal da análise qualitativa é compreender. Para isso,

[...] é preciso levar em conta a singularidade do indivíduo, porque sua subjetividade é uma manifestação do viver total. Mas também é preciso saber que a experiência e a vivência de uma pessoa ocorrem no âmbito da história coletiva e são contextualizadas e envolvidas pela cultura do grupo em que ela se insere. [...] Ao buscar compreender é preciso exercitar também o entendimento das contradições: o ser que compreende, compreende na ação e 
na linguagem e ambas têm como características serem conflituosas e contraditórias pelos efeitos do poder, das relações sociais de produção, das desigualdades sociais e dos interesses. Interpretar é um ato contínuo que sucede à compreensão e também está presente nela: toda compreensão guarda em si uma possibilidade de interpretação, isto é, de apropriação do que se compreende (MINAYO, 2012, p. 623).

A organização dos dados dos grupos focais e questionários se deram com base nos preceitos teórico-metodológicos que fundamentam esta pesquisa e nas orientações de Minayo (2012). A partir disso, os dados foram reestruturados em unidades de sentido (MINAYO, 2012) e iniciou-se a construção dos eixos de análise. Foram definidos dois eixos gerais e sete unidades de sentido. Para facilitar a compreensão, foi construída a tabela 1, que evidencia os aspectos abordados:

\section{Quadro 1 - Eixos de Análise}

\begin{tabular}{|l|l|l|}
\hline \multicolumn{1}{|c|}{ EIXOS } & \multicolumn{1}{|c|}{$\begin{array}{c}\text { UNIDADES DE } \\
\text { SENTIDO }\end{array}$} & \multicolumn{1}{c|}{\begin{tabular}{c}
\multicolumn{1}{c|}{ PROCEDIMENTOS } \\
UTILIZADOS
\end{tabular}} \\
\hline $\begin{array}{l}\text { Sentidos discentes sobre a } \\
\text { própria saúde mental. }\end{array}$ & $\begin{array}{l}\text { Expectativas anteriores; } \\
\text { O ingresso ao IF; } \\
\text { O sentido utilitarista de } \\
\text { educação e EMI; } \\
\text { A possibilidade da } \\
\text { evasão. }\end{array}$ & $\begin{array}{l}\text { Leitura, organização, } \\
\text { tipificação e síntese das } \\
\text { transcrições dos grupos focais e } \\
\text { dos questionários. }\end{array}$ \\
\hline $\begin{array}{l}\text { Relações entre ambiente } \\
\text { escolar, estrutura } \\
\text { curricular e saúde mental. }\end{array}$ & $\begin{array}{l}\text { Relações escolares; } \\
\text { Estrutura curricular; } \\
\text { Discurso dos docentes } \\
\text { sobre saúde mental. }\end{array}$ & $\begin{array}{l}\text { Leitura, organização, } \\
\text { tipificação e síntese das } \\
\text { transcrições dos grupos focais e } \\
\text { dos questionários. }\end{array}$ \\
\hline
\end{tabular}

Fonte: Questionários e grupos focais aplicados pelos autores.

O primeiro eixo de análise traz a compreensão e os sentidos dos discentes participantes sobre a própria saúde mental no contexto escolar. Dentre os materiais analisados estão as transcrições dos grupos focais e os questionários online. O segundo eixo de análise versa sobre as relações feitas pelos participantes entre ambiente escolar, estrutura curricular e saúde mental. Dentre os materiais analisados estão, também, as transcrições dos grupos focais e os questionários online.

A fim de preservar o anonimato dos participantes, durante o processo de análise os discentes foram nomeados por suas iniciais, enquanto os docentes pela letra "P" acompanhada de um número, de 1 a 17 . A análise de todos os dados coletados, por meio da trajetória 
construída, permitiu pensar e esboçar possíveis encaminhamentos, que constituíram o produto educacional desta pesquisa: uma formação continuada de professores. Todo o percurso investigativo, referencial teórico, coleta de dados e análises, trouxe as bases para a construção do produto educacional.

\section{RESULTADOS E DISCUSSÕES}

A descrição e discussão dos dados, neste trabalho, ocorreram de forma concomitante e vinculadas. Desta forma, são apresentados os eixos de análise, bem como o produto educacional resultante da pesquisa. O primeiro eixo é denominado "Sentidos discentes sobre a própria saúde mental" e o segundo, "Relações entre ambiente escolar, estrutura curricular e saúde mental". São explanadas as discussões possibilitadas em cada eixo de análise, além da construção, aplicação e análise do produto educacional.

\section{SENTIDOS DISCENTES SOBRE A PRÓPRIA SAÚDE MENTAL}

Para entender o discurso do outro, é preciso entender seu pensamento e não apenas algumas palavras (VIGOTSKI, 2001).

\footnotetext{
Os sentidos podem ser sempre vários, mas dadas certas condições de produção, não podem ser quaisquer uns. Eles vão se produzindo nos entremeios, nas articulações das múltiplas sensibilidades, sensações, emoções, sentimentos dos sujeitos que se constituem como tais nas interações; vão se produzindo no jogo das condições, das experiências, das posições, das posturas e decisões desses sujeitos; vão se produzindo numa certa lógica de produção, coletivamente orientada, a partir de múltiplos sentidos já estabilizados, mas de outros que também vão se tornando possíveis (SMOLKA,1988, p.12, apud MARTINS, 2018, p. 63).
}

Assim sendo, os sentidos dos discentes participantes da pesquisa vão se produzindo a partir de suas experiências particulares, sociais, familiares, escolares, nas diversas interações interpessoais, que são atravessadas pelo modo de produção capitalista vigente e suas regras mercadológicas; em um espaço da EPT, que também assume diferentes significados e sentidos.

Constatou-se, nesta pesquisa, que o ingresso ao instituto é o resultado de uma construção subjetiva que tem início nas experiências escolares anteriores, que é carregada de aspectos do imaginário social sobre a educação oferecida pelos IFs, propagada muitas vezes por docentes do ensino fundamental e familiares. Pereira (2017) explicita que a percepção que a sociedade 
tem sobre o sistema educativo é o que orienta os sujeitos à escolha da escola. Dos 10 discentes que responderam ao questionário online, 09 assinalaram que escolheram o IF para ter uma educação pública de qualidade.

Em uma sociedade que tem vivido experiências de fracasso com a escola, principalmente a escola pública, os IFs surgem como referência positiva de educação e qualidade. Para Bourdieu e Champagne (2008, p. 483),

[...] a instituição escolar é vista cada vez mais, tanto pelas famílias como pelos próprios alunos, como um engodo e fonte de uma imensa decepção coletiva: uma espécie de terra prometida, sempre igual no horizonte, que recua à medida que nos aproximamos dela.

É compreensível, portanto, que os IFs assumam, perante a sociedade, o significado de escola pública de qualidade, capaz de oferecer as melhores possibilidades de futuro. Depositamse nestas instituições as expectativas e desejos de futuros promissores na lógica neoliberal, mas não é mencionada, pelos discentes participantes, a filosofia de educação que a rede propõe: a proposta dos IFs “[...] é a de se constituir como instrumento do resgate da cidadania e da redução das desigualdades sociais, por meio da oferta de uma formação humanística, além da preparação técnica [...]" (JORGE, 2017, p.6-7).

Da mesma forma, Pereira (2017), em sua pesquisa, constatou que a opção pelo EMI está também vinculada à busca por um ensino médio de qualidade, estando esta associada, pelos jovens, a preparação para o vestibular e ingresso ao ensino superior. O EMI também se apresenta como semelhante ao ensino superior:

Um ensino de qualidade que oferece mais aos alunos do que em qualquer outra escola, é uma ótima preparação para o mercado de trabalho ou para cursos superiores, já que seu ritmo é semelhante aos mesmos (C., QUESTIONÁRIO).

Pereira e Bock (2018) pontuam esta comparação, apontando a carga horária exaustiva de um curso de EMI, comparando-o a um curso de engenharia. Pereira (2017) explica que:

No projeto pedagógico do curso para o técnico em automação industrial a carga é de 3.933 horas, e para o técnico em química, 3.900 horas e devem ser completas em três anos. É uma carga horária semelhante a um curso de engenharia. Em um PPC de outro campus, da mesma instituição em que foi feita a pesquisa, verificamos que a estrutura curricular do curso de engenharia 
em controle e automação é composta por 3.870 horas a serem cursadas em 10 semestres (PEREIRA, 2017, p.73).

De modo semelhante, no que se refere a presente pesquisa, o EMI em Automação Industrial possui carga de 3.695 horas, enquanto o EMI em Química possui carga de 3.723 horas. Ambas as cargas horárias incluem os estágios. Nota-se que os cursos da presente pesquisa possuem carga horária menor que a dos cursos investigados por Pereira (2017) e devem ser completados em quatro anos. Mesmo assim, há uma aproximação das cargas horárias dos EMI em Automação Industrial e em Química com a carga do curso de engenharia apontada pela autora. Além disso, percebe-se que o curso de Química possui uma carga horária ligeiramente maior que o curso de Automação Industrial.

As constatações realizadas até o momento permitem inferir que os discentes não escolheram o instituto por afinidade com o curso técnico ou pelo EMI, mas sim pelo ideal social e familiar, bem como pela promessa de um futuro promissor com relação ao vestibular e ao mercado de trabalho. Como observado, o meio social e a família exercem influências no processo de escolha pelo instituto ao valorizarem a modalidade de ensino profissional como facilitadora de empregabilidade, ou mesmo por se tratar de uma educação de qualidade financeiramente acessível comparada às escolas da rede privada, visto que são jovens da classe trabalhadora. É possível concluir que a escolha para o EMI é influenciada por múltiplas determinações implicadas na ideologia capitalista de mercado e de sociedade.

Os ingressantes criam, a partir disso, suas expectativas e representações sobre a educação oferecida por esta instituição escolar. Por vezes, esse ingresso pode não corresponder, de imediato, a esse imaginário. É um momento de adaptações, devido à saída do ensino fundamental, à entrada no ensino médio, em uma escola cujo currículo é diferente da estrutura anterior. Além disso, novas relações interpessoais se estabelecem, seja com os docentes ou com os demais colegas. Há quem veja esse momento como uma possibilidade promissora para o crescimento pessoal, amadurecimento. Mas nem todos sentem essa experiência da mesma forma.

Alencar e Sá (2017) também evidenciaram o período crítico em que se configura o primeiro ano do EMI. É um momento de dificuldades e angústias, que influenciam o desenvolvimento psicossocial e o desempenho acadêmico. Faria (2017) descreve também esta experiência como permeada de angústia e ansiedade, desgaste emocional, dificuldade para 
dormir e para se alimentar, dificuldade para acompanhar o ritmo de atividades do instituto, principalmente para os discentes do EMI, que são predominantemente das classes populares. Os discentes ingressantes desses cursos “[...] percebem seu novo ambiente escolar muitas vezes como gerador de estimulações excessivas, que levam à ansiedade" (FARIA, 2017, p. 88).

É necessário atentar-se para as repercussões disso à saúde dos discentes. Para Alencar e Sá (2017, p. 19), “a qualidade dessa transição vai depender tanto do desenvolvimento psicossocial do aluno, de suas vivências anteriores, como também da instituição e dos mecanismos de apoio colocados à disposição deles"; além da posição social de origem destes discentes. Em essência, o que temos na escola é a expressão da luta de classes.

O trecho a seguir descreve o "choque de realidade", nos termos desta participante, enfrentado pelos discentes que ingressam ao instituto, saídos de escolas públicas:

[...] aqui esse ano entrou por nota. Aí todo mundo que foi entrando tinha notas boas tipo, oito, a maioria tirava tudo dez. E acabou sendo um choque de realidade, por que a gente sai de um lugar onde só tirava dez, ou só tirava nove, ou então que era mais fácil assim pra tirar nota do que aqui. [...] eu nunca tirei uma nota vermelha na vida, fui tirar bimestre passado em biologia, né? E é muito ruim, porque você se sente muito mal. Até os pais. Meu pai é uma cobrança danada em casa, pra ele se a nota for abaixo de oito, pra ele é vermelho, entendeu? Acho que acaba sendo uma cobrança muito maior, porque os pais começam a pensar: ah, porque na outra escola você tirava só dez e chega aqui nessa, que você lutou tanto pra tá aí, você tá tirando nota baixa? (J., GRUPO FOCAL, grifo nosso).

Os discentes pesquisados trazem, como pontuado por Broccolichi (2008, p. 509), “[...] um sentimento de fracasso ligado ao sentimento de ocupar a partir de agora uma posição desvalorizada dentro da hierarquia escolar". O relato da participante se aproxima ao que descreve Broccolichi (2008, p. 510) sobre esta experiência no liceu de 1919, uma “[...] saudade de seu colégio, no qual era boa aluna, exceto em matemática, dando conta de tudo sozinha, sem pedir nada a seus pais [...] que tinham confiança nela".

As experiências descritas por Broccolichi (2008), sobre os discentes das classes populares do liceu, se apresentaram no discurso dos participantes desta pesquisa.

Fazendo parte até então dos "bons alunos" [...], elas ficaram particularmente surpresas e chocadas com o tratamento reservado a suas novas dificuldades [...]; elas se viram de repente confrontadas com a violência que o mundo 
escolar exerce sobre os alunos menos preparados para as suas exigências (BROCCOLICHI, p. 505, 2008).

Pereira (2017) também constatou o estranhamento acerca do rendimento obtido pelos discentes no IF, comparado à escola anterior. Percebeu que os discentes sofrem, principalmente nas disciplinas de exatas, com o novo padrão de exigências. Entram em ação cobranças externas, familiares e escolares, e internas, originadas nas expectativas sobre a escola, com base no imaginário social, na razão neoliberal, na lógica meritocrática.

Todavia, é preciso se atentar para o perigo de responsabilizar o discente, ser social, pelo impacto em sua saúde mental. Os sofrimentos psíquicos não tem apenas uma causa, são experiências multicausais, e o próprio ambiente escolar influencia esta questão.

A lógica neoliberal de produção de mercadoria, razão instrumental, perpassa todas as relações sociais e afeta profundamente a subjetividade. No país, ocorre

[...] a consolidação do modelo de sociedade neoliberal, apoiada na globalização dos mercados [...], a qual, por sua vez, é viabilizada e potencializada pelos avanços tecnológicos, principalmente, pelas chamadas tecnologias da informação e da comunicação - TIC -, [...], de modo que a distância entre os incluídos e os excluídos aumenta cada vez mais. Infelizmente, esse panorama é coerente com a lógica do mercado global (MOURA, 2008, p. 25).

O sistema neoliberal capitalista pauta também os conhecimentos produzidos no espaço educacional dos IFs. A produção em larga escala e em menor tempo possível, próprias das regras mercadológicas, entre outras formas de expressão da razão neoliberal, atravessam o espaço escolar e a produção do conhecimento. O trabalho em sua forma de produção social, que varia de acordo com o modo de produção vigente, determina e orienta a especificidade do currículo escolar (SAVIANI, 2007). Isso é também o que caracteriza o trabalho como princípio educativo. Em um sistema de produção que tem a precarização do trabalho como sustentáculo para sua sobrevivência (ANTUNES, 2009), os resultados na educação são tão maléficos, quanto no mundo do capital.

No entanto, o papel basilar do ensino médio é recuperar a relação entre a prática do trabalho e o conhecimento; promover o domínio teórico e prático sobre a forma que o conhecimento se articula ao processo produtivo (SAVIANI, 2007). Desta forma, o trabalho como princípio educativo formará politécnicos, no sentido de Saviani (2007), 
instrumentalizados para a transformação do modo de produção vigente e para a humanização de si, construindo sua essência humana, a partir do trabalho que constitui sua subjetividade. A noção desta articulação, como proposta por Saviani (2007), não foi encontrada no discurso dos discentes desta pesquisa.

Do mesmo modo, Pereira e Bock (2018) encontraram um forte caráter utilitarista nas significações acerca da experiência de escolarização dos alunos do EMI do IFSP. Esses discentes entendem que a responsabilidade sobre a preparação e ingresso, tanto no mercado de trabalho como na universidade, é do sujeito, o que pode culminar na culpabilização e responsabilização do indivíduo por seu fracasso ou sucesso.

De acordo com Moura (2008), a sociedade neoliberal tem como uma de suas características a responsabilização dos sujeitos por não possuírem “[...] condições de empregabilidade, apesar da própria estrutura socioeconômica não garantir os direitos que levariam os cidadãos a terem melhores condições de participação política, social, cultural e econômica [...]”' (p. 26). Por conseguinte, o EMI é ainda compreendido por esses discentes por meio de uma lógica meritocrática, que pode ser potencializada pela própria prática institucional.

Assim como em Pereira e Bock (2018), há um caráter utilitarista no discurso dos discentes participantes da atual pesquisa. Vale destacar que esse utilitarismo não é algo exclusivo dos discentes do EMI ou mesmo dos docentes, mas é inerente à sociedade capitalista vigente. A experiência educacional como um todo não é percebida como a "[...] possibilidade de desenvolvimento pessoal, no sentido da aquisição ou elaboração da cultura social em um processo de humanização e socialização" (PEREIRA, 2017, p. 75), mas como um investimento para o futuro. Tal qual encontrado na pesquisa de Pereira (2017), o ingresso dos discentes ao instituto denota o acesso a um projeto intermediário que servirá de mola propulsora para outros projetos.

Essa preparação, se pensada pela lógica neoliberal (MOURA, 2008; ANTUNES, 2009), é mecanicista e operacional, que não supre a plena formação humana e que concebe uma perspectiva de trabalho alienada, em detrimento do trabalho como constituição social e humana. A formação integral retira o foco do mercado de trabalho para voltar-se para o sujeito em suas potencialidades e necessidades, em sua omnilateralidade (SAVIANI, 2003, 2007). As perspectivas de futuro e projetos de vida desses discentes expressam uma apropriação da ideologia capitalista. 
Esse raciocínio utilitarista de educação deixa claro o sentido da escola redentora de todos os problemas sociais; a escola que detém, sozinha, a solução de todos os conflitos sociais, como promessa de um futuro melhor. Uma visão equivocada, já que a escola é também atravessada pelo sistema de produção, pela cultura mercadológica. E não é a salvadora das desigualdades e misérias sociais. Estas são produzidas pelo sistema neoliberal, que cultua o acúmulo de produção e o trabalho humano precarizado (ANTUNES, 2009).

A possibilidade da evasão emerge como fonte de reflexão frente à decisão de permanecer no instituto, mesmo vivenciando sofrimentos psíquicos. Estes sofrimentos foram frequentemente externalizados por meio do sentimento de incapacidade. Algumas das falas dos participantes são representativas:

[...] muitas vezes você se sente incapaz (A.; GRUPO FOCAL).

[...] principalmente a matéria técnica, tem um peso muito grande, tipo assim de sofrer demais por ela, chorar o tempo todo, de me sentir: nossa, sou muito incapaz de fazer isso aqui e tal (B., GRUPO FOCAL).

A vontade de desistir é uma questão recorrente no discurso dos discentes pesquisados, o que pode denotar um sofrimento latente e significativo resultante da vivência com o curso e o ambiente escolar.

A partir de todo o exposto até o momento, pode-se compreender o sentido atribuído pelos discentes à própria saúde mental como algo construído e estabelecido a partir de suas relações interpessoais e experiências escolares, que se evidenciou no fato dos discentes considerarem a qualidade da formação do EMI do IF, mas que traz repercussões negativas à saúde mental, principalmente no período de ingresso ao IF, momento de adaptação do discente ao instituto.

Portanto, as experiências escolares de ingresso ao IF não ocorrem livres de algum prejuízo para a saúde mental dos discentes. A defesa destes em priorizar convicções e crenças provenientes do imaginário social sobre o instituto e a constatação do novo cenário e ritmo acadêmicos revelam um desgaste físico e mental, decorrente do enfrentamento desta nova experiência escolar. Esse esgotamento psíquico é o resultado dos conflitos e impasses desses discentes, que inevitavelmente, surgem no período de adaptação ao IF. Nota-se que os sentidos atribuídos às condições formativas vivenciadas no EMI do IF vão ao encontro da lógica neoliberal e o sentido utilitarista de educação. 


\section{RELAÇÕES ENTRE AMBIENTE ESCOLAR, ESTRUTURA CURRICULAR E SAÚDE MENTAL}

Durante a pesquisa, principalmente na realização dos grupos focais, o discurso dos discentes se direcionava à dinâmica da relação entre docentes e discentes. Foi possível constatar conflitos na comunicação, principalmente quando a questão está relacionada aos sofrimentos que os discentes sentem no ambiente escolar. Na relação entre os próprios discentes, identificaram-se as comparações de rendimento:

Eu acho também que existe problema na sala mesmo, os alunos compararem uns aos outros. Já escutei uma pessoa da minha sala falando os top cinco da sala. E tipo, isso acaba comigo. [...] eu não acho justo ter um melhor, porque todo mundo tá se esforçando. (A. C.; GRUPO FOCAL).

[...] no terceiro bimestre, acho que foi muito crítico [...] de me sentir extremamente insegura, me comparando muito a todo mundo [...] e me fazendo bastante mal (B., GRUPO FOCAL).

Essa comparação, suscetível de um ambiente escolar competitivo, foi mencionada também pelos docentes, ao refletirem sobre as possíveis influências para a saúde mental, que a estrutura curricular e o ambiente escolar do IF podem causar:

Sobretudo, a criação de um ambiente altamente competitivo e com grande número de disciplinas (P9, QUESTIONÁRIO).

[...] pouco se reflete de fato sobre o clima competitivo e excludente criado com os alunos (P3, QUESTIONÁRIO).

Os docentes pesquisados trazem a relação entre estrutura curricular, ambiente escolar e saúde mental ao apontar a questão, também importante e muito pesquisada, da saúde mental docente:

Uma estrutura curricular mal distribuída, mal organizada, que não atende as necessidades dos alunos, uma carga horária que não permite desenvolver ou cumprir o que é preciso na disciplina que você leciona prejudica a sua saúde mental. Você tem a sensação de que não desempenha bem o seu papel de educador. Fica sempre uma angústia quando percebe que há muito conteúdo que não foi trabalhado. Se houvesse mesmo uma integração do currículo entre as disciplinas técnicas e as do núcleo comum, isso amenizaria essa angústia (P4, QUESTIONÁRIO). 
Além do sofrimento discente latente, anunciado pelo olhar docente, a fala revela ainda o sofrimento docente presente na relação saúde mental, ambiente escolar e estrutura curricular. É possível pensar que este discurso "denuncia também uma precarização na organização do trabalho docente, que frequentemente se resume ao fazer, ao 'dar aulas', ao colocar em prática um planejamento muitas vezes já elaborado de antemão” (MARTINS, 2018, p. 74). Este cenário do trabalho docente assemelha-se a produção fabril, em larga escala, que acaba por alienar o trabalhador do seu processo de trabalho e do produto final que produziu.

Os docentes participantes, portanto, afirmaram existir relação entre as questões escolares e a saúde mental, não só para os discentes, mas todos os docentes envolvidos. Também foi pontuado o caráter etnocêntrico do currículo como fator que pode afetar a saúde mental discente, já que a escola e o currículo reproduzem a luta de classes, o etnocentrismo, que são inerentes à lógica capitalista.

As marcas e sinais de embates e resistência no cotidiano da escola foram perceptíveis nos discentes e até mesmo docentes, com reações distintas, devido à personalidade e ao perfil de cada um, principalmente no que se refere às relações escolares. Por meio do discurso dos participantes, notaram-se contradições nas posturas de discentes e docentes, frente às problemáticas de saúde mental na escola, que oscilam entre aceitação e resistência, indiferença e envolvimento, submissão e confronto (SHERMACK, 2015), diante das condições expostas no ambiente escolar do IF.

Posturas de iniciativa e resistência são necessárias para a promoção da saúde mental no ambiente escolar, mas existem questões ideológicas e institucionais "[...] que são difíceis de serem resolvidas apenas com a iniciativa pessoal e boa vontade" (SHERMACK, 2015, p.155). Exemplos disso são a estrutura curricular abarrotada e não integrada e a falta de compreensão sobre a concepção de EMI e EPT por muitos dos docentes e discentes pesquisados, o que é uma questão não de responsabilidade apenas destes, mas de competência dos órgãos administrativos superiores, que precisam instrumentalizar, de forma mais efetiva, seus servidores com as bases conceituais do campo de ensino em que atuam. Consequentemente, isso acaba prejudicando reflexões mais profundas sobre a temática e ações que promovam a saúde mental discente dentro do ambiente escolar, atreladas aos pressupostos de desenvolvimento omnilateral do discente do EMI.

As relações escolares são fatores que emergem no discurso dos participantes, tanto docentes como discentes, enquanto elementos importantes para a promoção ou prejuízo da 
saúde mental. Entre os discentes, o estranhamento no ambiente escolar atual não está apenas ligado às novas relações estabelecidas entre eles e os docentes, mas também à perda da escola anterior e das experiências escolares gratificantes, para o impacto com as exigências escolares atuais.

Ademais, alguns elementos vinculados à ideologia neoliberal na educação podem ser entendidos de formas distintas pelos docentes, devido sua história pessoal e profissional. Foi possível, assim, verificar em seus discursos os desafios impostos à educação decorrentes da configuração sócio-político-econômica atual, mas que pouco é relacionado pelos participantes às questões de saúde mental discente.

Ficaram constatadas as relações entre as questões escolares e a saúde mental, não só para os discentes, mas para os docentes envolvidos. O espaço ofertado para esta relação foi utilizado pelos docentes para a expressão dos seus próprios sofrimentos vinculados ao currículo e ao ambiente escolar.

\section{PRODUTO EDUCACIONAL ${ }^{4}$}

Para o desenvolvimento da formação docente sobre a saúde mental discente foi construído inicialmente um plano de ensino para organização do conteúdo a ser abordado, bem como da dinâmica de trabalho. A formação se constituiu em três encontros.

O primeiro encontro teve duração de duas horas e participaram 29 docentes do EMI, que foram convocados para a atividade pelo Diretor de Ensino do Câmpus, que também assistiu à formação. Neste dia, foram apresentados os objetivos, o tema e o produto educacional da pesquisa. Foram introduzidos, de forma expositiva e dialogada, os conceitos de saúde mental e sofrimento psíquico, bem como os conteúdos referentes aos dados e análises da pesquisa, sem a exposição de nenhuma informação de identificação dos participantes. Para isso, foram usados slides para apoio das atividades desenvolvidas no encontro.

A proposta de formação continuada foi inicialmente pensada e idealizada apenas para os docentes do EMI, tendo em vista o público alvo desta pesquisa. Após a realização do primeiro encontro, os participantes sugeriram que o conteúdo da formação fosse estendido para todos os docentes do Câmpus, visto que consideraram que todos podem, em algum momento, ministrar aulas para os cursos técnicos integrados, bem como entenderam o conteúdo da

\footnotetext{
${ }^{4}$ Link para o produto educacional na Plataforma EDUCAPES: http://educapes.capes.gov.br/handle/capes/559858
} 
formação como importante para todos os docentes, independente do curso. Desta forma, o terceiro encontro foi elaborado após esta sugestão, sendo que os dois encontros finais foram programados para os dois dias de planejamento semestral do Câmpus, momento em que todos os servidores estariam reunidos para o retorno ao semestre letivo, sendo oportuno para a continuidade da formação.

O segundo encontro, portanto, ocorreu com um intervalo de 42 dias do primeiro, com duração de duas horas e participação de 73 docentes, bem como do Diretor Geral, da Diretora Adjunta Acadêmica e do Diretor de Ensino. Neste encontro, foram inicialmente apresentados os objetivos, o tema e o produto educacional da pesquisa. Foram explicitados os motivos pelos quais a formação foi estendida para todos os docentes do Câmpus. Em seguida, foram retomados alguns conteúdos do primeiro dia de formação, a fim de contextualizar os novos participantes. Posteriormente, foram apresentados, de forma expositiva e dialogada, os conteúdos planejados para esse encontro, que foi finalizado com a discussão de um caso fictício, embasado na pesquisa realizada.

O terceiro encontro foi realizado no segundo dia do planejamento semestral do Câmpus, com duração de aproximadamente 90 minutos e participação de 67 docentes, bem como do coordenador da CSP, do Diretor Geral, da Diretora Adjunta Acadêmica e do Diretor de Ensino. Inicialmente, foram retomados, rapidamente, os conteúdos dos encontros anteriores e em seguida foram abordados, de forma expositiva e dialogada, a atuação do psicólogo escolar e os conceitos de fatores de risco e proteção à saúde mental, sendo esse encontro também finalizado por meio da discussão de um caso fictício, embasado na pesquisa.

A fim de avaliar a formação ofertada para os docentes, foram elaborados e aplicados dois questionários online para os participantes: um apenas para os docentes e outro para os gestores e coordenadores. Os questionários foram enviados por e-mail para todos os participantes da formação, tendo obtido 12 respostas docentes e 03 dos gestores. Foram enviados, também por e-mail, lembretes para que os questionários fossem respondidos. Mesmo assim, o número de respostas foi pequeno, comparado ao número de participantes da formação.

O processo de análise destes questionários também utilizou as orientações sobre a organização dos dados de Minayo (2012). Durante o processo de análise dos questionários, os docentes foram nomeados pela letra "P" acompanhada de um número de 1 a 12, e os gestores pela letra "G" acompanhado de um número de 1 a 3 , a fim de assegurar o anonimato dos participantes. 
Dos 15 participantes que responderam aos questionários online, 11 ficaram satisfeitos com o conteúdo da formação, 03 não ficaram satisfeitos nem insatisfeitos e 01 não ficou satisfeito. Sobre a relevância da formação para o trabalho de cada participante, 10 consideraram ser relevante, 04 não consideraram relevante nem irrelevante e 01 considerou irrelevante. Sobre os pontos mais importantes da formação, apontaram a apresentação do conceito de sofrimento psíquico, as discussões de casos, a possibilidade de poder refletir sobre a prática docente, a temática referente à integração curricular, relações sobre saúde mental e currículo, bem como a abordagem da saúde mental discente.

A análise da formação ofertada revelou a importância da construção de um espaço para reflexão coletiva sobre a temática, como encontrado na revisão bibliográfica e recomendações teóricas. Um espaço para pensar e levantar estratégias de ação em conjunto, a partir de suas experiências, mais que a necessidade da exposição de conceitos e conteúdos teóricos.

Ao refletirem sobre a formação de professores, Nörnberg e Pereira (2015, apud MARTINS, 2018), legitimam esta percepção ao explicarem que:

[...] a aprendizagem em comum facilita a consolidação de dispositivos de colaboração profissional e a concepção de espaços coletivos de trabalho pode constituir um excelente instrumento de formação. É no espaço coletivo que os sujeitos se veem diante da oportunidade de revelar seus saberes, suas lógicas, suas dúvidas. Enfim, as posições teórico-práticas e as crenças que sustentam são postas em circulação (p. 3).

A formação realizada trata-se de um passo para um processo de trabalho preventivo de sofrimentos psíquicos de discentes do EMI e de promoção à saúde mental destes mesmos discentes. Esta formação não almejou solucionar as problemáticas envolvendo o tema, mas fomentar a reflexão e a construção de estratégias de ação pelos próprios docentes. Este é um trabalho que não deve se findar nesta proposta, mas espera-se que este seja o início de ações contínuas na instituição sobre a temática, pois este é um processo em construção.

Para Moura (2008) a formação e qualificação precisam

[...] ir além da aquisição de técnicas didáticas de transmissão de conteúdos para os professores e de técnicas de gestão para os dirigentes. Evidentemente, esses aspectos continuarão sendo importantes, mas o objetivo macro é mais ambicioso e deve privilegiar a formação no âmbito das políticas públicas do país, principalmente as educacionais, numa perspectiva de superação do modelo de desenvolvimento socioeconômico vigente, de modo que se deve 
priorizar mais o ser humano do que, simplesmente, as relações de mercado e o fortalecimento da economia (MOURA, 2008, p. 30).

Destarte, os IFs seguramente podem se tornar "[...] ambientes em que se constroem as condições para a promoção do bem-estar individual e coletivo" (BRITO, 2017, p. 158). Resultados satisfatórios, das ações promotoras de saúde na escola, somente ocorrerão com a participação e envolvimento de toda a comunidade escolar: discentes, docentes, funcionários e pais ou responsáveis, a partir do pensamento crítico e científico.

\section{CONSIDERAÇÕES FINAIS}

Constatou-se que o primeiro ano do EMI se configura como um momento crítico para os discentes. É um momento de adaptação ao novo contexto escolar, de dificuldades e angústias, que influenciam o desempenho acadêmico das classes populares. As experiências escolares de ingresso ao EMI não ocorrem livres de algum prejuízo para a saúde mental dos discentes pesquisados.

A forma em que está estruturado o currículo integrado pode gerar situações de estresse e sofrimento tanto para os discentes como para os docentes. Pode-se pensar, todavia, que não é o excesso de disciplinas ou atividades que adoecem os discentes, mas sim as contradições dadas pela desigualdade social que se expressam nas relações sociais e de opressão, legítimas e sutis. A reprodução social da escola é também fonte do sofrimento dos discentes: preconceito de classe, de gênero, relação de opressão e autoritarismo. Isto é, o sofrimento psíquico discente está atrelado a outros fatores para além do excesso de atividades no EMI, se pensarmos que são filhos da classe trabalhadora, seres sociais; têm a percepção de precarização do trabalho e sofrem o mal-estar geral da sociedade mediada pelo capital.

Desta forma, algumas questões podem ser levantadas para pesquisas futuras. Quem são esses discentes que mais sofrem? A intensidade desse sofrimento é maior no discente de qual gênero? A renda familiar desses discentes é menor que a da média? Entre os jovens da classe trabalhadora mais precarizada esses sofrimentos são mais agudos ou latentes? Quem são esses docentes que atuam com esses discentes? Os docentes do EMI dos IFs trabalham comprometidos com a superação da dualidade histórica da escola? Estas questões exigem a apropriação de dados sobre classe social e trajetória escolar e profissional dos sujeitos da pesquisa. 
Em teoria, o currículo integrado, em seu sentido mais profundo, pode promover a saúde mental de discentes ao concebê-los como seres construídos em suas relações sociais, nas quais podem atuar de forma a transformá-las, desde que seu processo de ensino-aprendizagem proporcione a construção do pensamento crítico e a possibilidade de desenvolvimento de suas potencialidades, enquanto ser humano. Todavia, não se pode esquecer que a escola atual reproduz várias formas de violência. A contradição está na própria escola.

A formação continuada proposta e desenvolvida como produto educacional se apresentou como uma atuação na contradição do sistema capitalista, já que toda ação emancipadora se dará na contradição, como uma tentativa de trilhar um caminho mais humanista na escola, em detrimento da reprodução e legitimação da lógica capitalista na instituição escolar. Mesmo assim, foi possível pontuar resultados positivos, mas demonstrou ser uma ação limitada, se concebida de forma isolada.

Outra proposta de encaminhamento que poderia ser pensada seria uma formação sobre EPT e saúde mental para os servidores que ingressam na EPT, como um processo de ambientação ou acolhimento ao novo campo de trabalho, a fim de abordar com esses novos servidores as especificidades e bases conceituais da EPT, sua filosofia de educação, bem como as relações com a saúde mental discente e de todos os educadores.

Chamou à atenção a constatação pelos participantes de haver mais discentes em sofrimento psíquico no EMI em Química. Isso pode ser relacionado também com o fato de a maioria dos discentes que se dispuseram a participar da pesquisa ser da Química. Apenas dois participantes são discentes do EMI em Automação Industrial. Este é um dado que merece atenção e pode ser verificado em pesquisas futuras.

Por fim, entende-se que para os discentes pesquisados a relação social - na escola, entre discentes e instituição, entre discentes e docentes - gera sofrimento. Já para os docentes é uma questão individual: do discente e de suas condições pessoais que antecedem à escola. Esta contradição está explicita na pesquisa. Trata-se da luta de classes simbólica presente na instituição escolar: a classe média, cuja ideologia é meritocrática, versus a classe trabalhadora. Entende-se, portanto, que a saúde mental não é um fenômeno isolado; há determinações históricas e sociais para a saúde mental desses discentes. Neste sentido, as propostas em contexto escolar devem se dar no sentido da práxis; para compreender a relação entre o particular e o geral; sujeito e sua realidade social e objetiva. 


\section{REFERÊNCIAS}

ALENCAR, E. R. D.; SÁ, I. R. M. R. Boas vindas, técnico: acolhimento e prevenção ao bullying na escola. In: NEGREIROS, F.; SOUZA, M. P. R. (Orgs). Práticas em psicologia escolar: do ensino técnico ao superior. $1^{\text {a }}$ ed., vol. 2, Teresina: EDUFPI, 2017. p. 15-31.

ANTUNES, R. Os sentidos do trabalho: ensaio sobre a qualificação e a negação do trabalho. São Paulo: Boitempo. 2009.

BOURDIEU, P.; CHAMPAGNE, P. Os excluídos do interior. In: BOURDIEU, P. (Coord.). A miséria do mundo. $7^{\text {a }}$ ed., Petrópolis: Vozes, 2008, p. 481-486.

BRITO, D. D. S. A escola como um espaço de construção para a promoção da saúde mental: um relato de experiência. In: NEGREIROS, F.; SOUZA, M. P. R. (Orgs). Práticas em psicologia escolar: do ensino técnico ao superior. $1^{\mathrm{a}}$ ed., vol. 4, Teresina: EDUFPI, 2017. p. 155-166.

BROCCOLICHI, S. Um paraíso perdido. In: BOURDIEU, P. (Coord.). A miséria do mundo. $7^{\text {a }}$ ed., Petrópolis: Vozes, 2008, p. 505-514.

FARIA, A. A. G. T. Experiências e sentidos da escola na perspectiva dos jovens no Instituto Federal de Alagoas - IFAL. In: NEGREIROS, F.; SOUZA, M. P. R. (Orgs). Práticas em psicologia escolar: do ensino técnico ao superior. $1^{a}$ ed., vol. 2, Teresina: EDUFPI, 2017. p. 78-94.

IERVOLINO, S. A.; PELICIONI, M. C. F. A utilização do grupo focal como metodologia qualitativa na promoção da saúde. Revista da Escola de Enfermagem da USP. São Paulo, v. 35, n. 2, p. 115-21, jun. 2001. Disponível em: < http://www.scielo.br/scielo.php?pid=S008062342001000200004\&script=sci_abstract\&tlng=pt $>$ Acesso em: 08 abr. 2018.

JORGE, J. P. Saúde mental discente: reflexões a partir da experiência como psicóloga escolar no Instituto Federal de Educação, Ciência e Tecnologia de São Paulo. In: NEGREIROS, F.; SOUZA, M. P. R. (Orgs). Práticas em psicologia escolar: do ensino técnico ao superior. $1^{\text {a }}$ ed., vol. 8, Teresina: EDUFPI, 2018. p. 93-103.

Psicologia escolar e educação profissional e tecnológica: uma prática em construção. In: NEGREIROS, F.; SOUZA, M. P. R. (Orgs). Práticas em psicologia escolar: do ensino técnico ao superior. $1^{a}$ ed., vol. 1, Teresina: EDUFPI, 2017. p. 35-52.

MARINHO-ARAÚJO, C. M.; ALMEIDA, S. F. C. Psicologia escolar: construção e consolidação da identidade profissional. Campinas: Alínea, 2010.

MARTINS, M. A. R. Sentidos atribuídos às relações formativas no âmbito do programa professor aprendiz. 2018. 126 f. Dissertação (Mestrado em Educação) - Universidade Federal de São Carlos, Sorocaba, 2018.

MINAYO, M. C. S. Análise qualitativa: teoria, passos e fidedignidade. Ciência \& Saúde Coletiva. Rio de Janeiro, v.17, n.3, p. 621-626, mar. 2012. Disponível em: < 
http://www.scielo.br/scielo.php?pid=S1413-81232012000300007\&script=sci_abstract $>$ Acesso em: 08 abr. 2018.

MOURA, D. H. A formação de docentes para a educação profissional e tecnológica. Revista Brasileira da Educação Profissional e Tecnológica. Natal, v. 1, n. 1, p. 23-38, 2008. Disponível em: < http://www2.ifrn.edu.br/ojs/index.php/RBEPT/article/view/2863> Acesso em: 10 jul. 2019.

PEREIRA, E. A.; BOCK, A. M. B. A dimensão subjetiva da escolarização de jovens do ensino médio integrado ao técnico em um campus do instituto federal de São Paulo. In: NEGREIROS, F.; SOUZA, M. P. R. (Orgs). Práticas em psicologia escolar: do ensino técnico ao superior. $1^{a}$ ed., vol. 8, Teresina: EDUFPI, 2018. p. 14-31.

PEREIRA, E. A. A dimensão subjetiva da escolarização profissional: um estudo com jovens do ensino médio integrado ao técnico em um campus darede federal. 2017. $133 \mathrm{f}$. Dissertação (Mestrado em Psicologia da Educação) - Pontifícia Universidade Católica de São Paulo, São Paulo, 2017.

SAVIANI, D. O choque teórico da politecnia. Trabalho, Educação e Saúde, v.1, n.1, p. 131152, 2003. Disponível em: < http://www.scielo.br/scielo.php?pid=S1981-

77462003000100010\&script=sci_abstract\&tlng=pt> Acesso em: 23 abr. 2018.

. Trabalho e educação: fundamentos ontológicos e históricos. Revista Brasileira de Educação. Rio de Janeiro, v. 12, n. 34, p. 152-180, jan./abr. 2007. Disponível em: <http://www.scielo.br/scielo.php?script=sci_arttext\&pid=S1413-24782007000100012> Acesso em: 23 abr. 2017.

SODRÉ, E. N. Processos de escolarização, sofrimento psíquico e medicalização da vida. In: NEGREIROS, F.; SOUZA, M. P. R. (Orgs). Práticas em psicologia escolar: do ensino técnico ao superior. $1^{\mathrm{a}}$ ed., vol. 2, Teresina: EDUFPI, 2017. p. 167-178.

SCHERMACK, L. V. A política de recuperação intensiva no estado de São Paulo: um estudo de caso sobre os sentidos de professores do ensino fundamental. 2015. $183 \mathrm{f}$. Dissertação (Mestrado em Educação) - Universidade Federal de São Carlos, Sorocaba, 2015.

VIGOTSKI, L. S. A construção do pensamento e da linguagem. São Paulo: Martins Fontes. 2001. 